\title{
Long-Term Cholic Acid Therapy in Zellweger Spectrum Disorders
}

\author{
James E. Heubi ${ }^{a, b} \quad$ Kenneth D.R. Setchell ${ }^{b} \quad$ Kevin E. Bove ${ }^{b}$ \\ aDivision of Pediatric Gastroenterology, Hepatology, and Nutrition, Cincinnati Children's \\ Hospital Medical Center, University of Cincinnati, Cincinnati, $\mathrm{OH}, \mathrm{USA}$; ${ }^{\text {b }}$ ivision of \\ Pathology and Laboratory Medicine, Cincinnati Children's Hospital Medical Center, \\ University of Cincinnati, Cincinnati, $\mathrm{OH}$, USA
}

\section{Keywords}

Bile acid synthesis · Cholic acid · Zellweger spectrum disorder · Liver function · Long-term treatment $\cdot$ Peroxisomal biogenesis disorder

\begin{abstract}
Zellweger spectrum disorders (ZSDs), a subgroup of peroxisomal biogenesis disorders, have a generalized defect in peroxisome function. Liver disease in ZSDs has been linked to accumulation of $\mathrm{C}_{27}$-bile acid intermediates due to the lack of peroxisomal $\beta$-oxidation of these intermediates to form primary $\mathrm{C}_{24}$-bile acids. Oral treatment with primary bile acid, cholic acid (CA), inhibits formation of hepatotoxic $\mathrm{C}_{27}$-bile acids by restoring normal physiologic feedback inhibition on bile acid synthesis. We present the long-term CA treatment and liver-related outcomes for 3 pediatric patients with ZSDs who have received CA treatment for $\geq 15$ years. Ongoing CA treatment was associated with stabilized liver function, as shown by serum biochemistries and liver histopathology, and no treatment-related adverse effects were observed. All 3 patients have attended regular school with classroom accommodations and attained a good quality of life. Our patient outcomes suggest that early and ongoing CA therapy may sustain liver function in patients with ZSDs.

(C) 2018 The Author(s)

Published by S. Karger AG, Basel
\end{abstract}




\section{Case Reports in Gastroenterology}

Case Rep Gastroenterol 2018;12:360-372

DOI: 10.1159/000490095

(c) 2018 The Author(s). Published by S. Karger AG, Basel www.karger.com/crg

Heubi et al.: Long-Term Cholic Acid Therapy in Zellweger Spectrum Disorders

\section{Introduction}

Peroxisomal biogenesis disorders have a generalized or specific defect in peroxisome function that interferes with fatty acid $\beta$-oxidation, bile acid synthesis, ether phospholipid biosynthesis, fatty acid $\alpha$-oxidation, glyoxylate detoxification, and/or L-pipecolic acid degradation [1]. Patients with Zellweger spectrum disorders (ZSDs, severe OMIM\#214100/mild OMIM\#601539), a subgroup of peroxisomal biogenesis disorders, exhibit wide-ranging clinical symptoms that can be categorized as relatively mild, intermediate, or severe [2,3]. Clinical features that may occur across the spectrum of ZSD severity include developmental delay and neurological abnormalities, seizures, liver dysfunction and hepatomegaly, vision and hearing impairment, and adrenocortical dysfunction [3].

Liver disease in ZSDs has been associated with the accumulation of the $\mathrm{C}_{27}$-bile acid synthesis intermediates di- and trihydroxy-cholestanoic acid (DHCA, THCA) [1, 4]. In ZSDs, bile acid synthesis is dysregulated due to the lack of peroxisomal $\beta$-oxidation of $\mathrm{C}_{27}$-bile acid intermediates that cannot undergo side-chain oxidation to form normal $\mathrm{C}_{24}$-primary bile acids. This results in loss of the normal feedback regulation of bile acid synthesis and further production/accumulation of $\mathrm{C}_{27}$-bile acid intermediates [5]. Oral treatment with primary bile acid, cholic acid (CA), inhibits formation of $\mathrm{C}_{27}$-bile acids from cholesterol via downregulation of bile acid biosynthesis through activation of the nuclear farnesoid $\mathrm{X}$ receptor, resulting in reduced transcriptional activation of cholesterol $7 \alpha$-hydroxylase, the rate-limiting enzyme in bile acid biosynthesis $[1,6]$. CA therapy in ZSD was first examined more than 20 years ago in an infant with severe ZSD and resulted in reduction in serum liver enzymes, decreased urinary $\mathrm{C}_{27}$-bile acids, and weight gain [7]. Additionally, the infant had a significant reduction in continuous seizures to 2-3 episodes a day [7]. Recently, 9-month CA treatment in ZSD patients without advanced liver disease significantly reduced levels of $\mathrm{C}_{27}$-bile acid intermediates [5], confirming the original observations of downregulation in bile acid synthesis by oral CA [7].

Oral CA (Cholbam ${ }^{\circledR}$; Retrophin, Inc., San Diego, CA, USA) was approved in March 2015 by the FDA for adjunctive treatment of peroxisomal disorders, including ZSD. The CA treatment outcomes in 20 ZSD patients included in the registration trial supporting FDA approval of CA for treatment of single-enzyme defects and adjunctive treatment for ZSDs were recently reported [8]. Normalized urinary bile acid excretion was found in $85.2 \%$ of ZSD patients following CA treatment, and there was a marked increase in the number of patients with serum liver enzyme levels below the upper limit of normal. However, specific responses of individual patients over the long-term course of CA therapy were not reported. Here we present the longterm CA treatment histories and liver-related outcomes for 3 patients with ZSDs initially treated with CA under an FDA Investigational New Drug (IND) application who have continued on CA. Patients 1 and 2, twins diagnosed with mild ZSD, began CA treatment at age 13 months and 19 months, respectively, and were 17 years old at the time of this report. Patient 3 , diagnosed with severe ZSD, began CA treatment at age 3 years and was 19 years old at the time of this report. We report on the metabolites produced because of peroxisomal dysfunction, liver histology in early infancy and childhood, serum liver chemistries, and quality of liferelated outcomes. 


\section{Case Reports in Gastroenterology}

Case Rep Gastroenterol 2018;12:360-372

DOI: $10.1159 / 000490095$

(c) 2018 The Author(s). Published by S. Karger AG, Basel www.karger.com/crg

Heubi et al.: Long-Term Cholic Acid Therapy in Zellweger Spectrum Disorders

\section{Methods}

The patients were treated with CA within an investigator-initiated compassionate use program (NCT00007020) followed by an open-label, nonrandomized, noncomparative clinical study (NCT01438411). These studies were approved by the Institutional Review Board of the Cincinnati Children's Hospital Medical Center. The parents of each patient provided informed consent for inclusion in the FDA IND studies and in this report.

Patients received clinical care at distant sites, and their local treating physicians provided patient laboratory data and urine samples for assessments. Data collection was not required at standardized study time points. Patients were allowed to continue other medications and medical care. Laboratory assessments of serum liver chemistries included alanine aminotransferase (ALT), alkaline phosphatase (ALP), aspartate aminotransferase (AST), and bilirubin and were performed in certified laboratories (Clinical Laboratory Improvement Act or College of American Pathologists). Percutaneous liver biopsies prior to CA treatment and up to 12 months following CA initiation were reviewed in Cincinnati by K.E.B., a pediatric pathologist. Standard methods were used for liver biopsy processing and section staining used hematoxylin, eosin, and trichrome. Peroxisome number was assessed using standard electron microscopy preparation techniques and exhaustive search without catalase markers. Data from mass spectral analysis of urinary bile acids performed with fast atom bombardment mass spectrometry (FAB-MS) were reviewed by K.D.R.S. using semiquantitative assessment of normal, slightly increased, significantly increased, or markedly increased levels of atypical bile acids.

\section{Patient 1}

\section{Clinical History}

Patient 1, a Hispanic male, was born prematurely in a twin pregnancy at gestational age 35 weeks and weighed $1.6 \mathrm{~kg}$ at birth. He required oxygen in the nursery and at postpartum age 3 weeks had a seizure and small intracranial hemorrhage secondary to vitamin K deficiency. He had a significant vitamin K-responsive bleeding tendency following immunization injections that resulted in hematomas. He had low energy, weakness, loss of appetite, hearing loss, and delayed visual maturation.

At age 5 months he had a markedly prolonged prothrombin time (PT) and no jaundice, hepatosplenomegaly, or pruritus, but had markedly increased serum and urine bile acids. Urine FAB-MS showed presence of taurine-conjugated trihydroxy- and tetrahydroxy-cholestanoic acids $\left(\mathrm{C}_{27}\right.$-bile acids) consistent with a defect in peroxisomal $\beta$-oxidation of THCA. Further testing resulted in a diagnosis of mild ZSD (Table 1).

Two liver biopsies were performed, the first prior to CA treatment. Histopathology at age 7 months showed moderate lobular disarray with prominent pseudoacinar transformation, minor focal periportal fibrosis, and minimal inflammation. Portal areas contained rare enlarged macrophages with slate-grey cytoplasm. Spotty hepatocyte necrosis and mitotic activity were uncommon. Steatosis, ductular proliferation, and cholestasis were absent. Liver ultrastructure showed no normal peroxisomes. Rare peroxisome-like structures showed matrix separation from membrane and a dense amorphous core. 


\section{Case Reports in Gastroenterology}

Case Rep Gastroenterol 2018;12:360-372

DOI: 10.1159/000490095

(c) 2018 The Author(s). Published by S. Karger AG, Base www.karger.com/crg

Heubi et al.: Long-Term Cholic Acid Therapy in Zellweger Spectrum Disorders

\section{Cholic Acid Treatment}

At age 13 months, when CA $15 \mathrm{mg} / \mathrm{kg} /$ day was started, the patient had frontal bossing, a liver that was firm and palpable $2-3 \mathrm{~cm}$ below the costal margin with a nonpalpable spleen, and mild developmental delay with no focal neurological findings. Serum ALT, ALP, and bilirubin were normal, but AST was elevated (Table 2). For a short period at the beginning of CA therapy, he received treatment with ursodeoxycholic acid. Histopathology following 7 months of CA treatment at age 20 months was mostly unchanged, indicating no progression of liver disease (Fig. 1a-d). Ongoing CA therapy dosing has ranged from 9 to $15 \mathrm{mg} / \mathrm{kg} / \mathrm{day}$, and at the time of this report, the patient has received CA treatment for 15.5 years without any treatment-related adverse events.

\section{Long-Term Outcome}

With ongoing CA treatment, FAB-MS showed a normal urinary bile acid profile consistent with resolution of the cholestasis (data not shown) and the serum liver chemistries stabilized (Table 2). The patient has attended regular school with classroom accommodations and continues to receive CA.

\section{Patient 2}

\section{Clinical History}

Patient 2, a Hispanic female and twin of patient 1, was born prematurely at gestational age 35 weeks, weighing $2.2 \mathrm{~kg}$. She had a 1-week stay in the newborn intensive care unit for feeding and had strabismus, nystagmus, and hearing loss. She was evaluated following her twin's ZSD diagnosis and was diagnosed with mild ZSD at age 15 months. A panel of peroxisomal metabolites (Table 1) and urine FAB-MS findings, including slight/mild elevation in urinary bile acid excretion, mild cholestasis, and presence of abnormal bile acid metabolites, were characteristic of a peroxisomal function disorder.

Before CA treatment, liver histopathology showed normal lobular architecture. Hepatocytes had clear expanded cytoplasm with subtle pseudoacini and a rare glycogen pseudonodule. Rare but conspicuous Kupffer cells and portal macrophages had expanded cytoplasm with a slate-blue tint that was positive with PAS diastase. Mild portal fibrosis with incomplete septa and focal sinusoidal fibrosis were present (Fig. 1e), and occasional storage-type Kupffer cells contained negatively staining linear inclusions (inset Fig. 1e). Liver ultrastructure failed to identify peroxisomes; Kupffer cells contained prominent dense polymorphous residual bodies without crystalloids. Pre-CA treatment serum ALT, AST, and ALP were elevated, whereas bilirubin and PT were normal (Table 1).

\section{Cholic Acid Treatment}

CA $15 \mathrm{mg} / \mathrm{kg} /$ day was initiated at age 19 months. Examination prior to CA was unremarkable except for nystagmus and a liver palpable $2 \mathrm{~cm}$ below the right costal margin without splenomegaly. Ongoing CA therapy has ranged from 9 to $15 \mathrm{mg} / \mathrm{kg} /$ day without any treatment-related adverse events. Her FAB-MS scores for urinary bile acid excretion normalized (data not shown), and serum liver chemistries stabilized (Table 2). 


\section{Case Reports in Gastroenterology}

Case Rep Gastroenterol 2018;12:360-372

DOI: $10.1159 / 000490095$

(c) 2018 The Author(s). Published by S. Karger AG, Basel www.karger.com/crg

Heubi et al.: Long-Term Cholic Acid Therapy in Zellweger Spectrum Disorders

\section{Long-Term Outcome}

The patient has attended regular school with classroom accommodations and successfully received a cochlear implant. She continues to receive CA treatment.

\section{Patient 3}

\section{Clinical History}

Patient 3, a Caucasian male, was a small-for-gestational-age, term infant born weighing $2.5 \mathrm{~kg}$. Severe ZSD was diagnosed at age 3 months, following newborn jaundice, feeding problems, malabsorption of fat-soluble vitamins, steatorrhea, failure to thrive, and hypotonia, and based on a peroxisomal metabolites panel (Table 1). The patient had impaired vision, impaired hearing, adrenal insufficiency, hepatomegaly, ataxia, and severe developmental delay with noted concerns about myelination.

Liver histology at initial ZSD diagnosis included bridging fibrosis with giant-cell formation. Approximately 13 months later, mild periportal inflammation, bridging fibrosis, and lobular cholestasis persisted. Liver histology at age 3 years, just prior to CA therapy, included intact lobular architecture, but hepatocytes generally showed a mosaic architecture with occasional pseudoacinar transformation (Fig. 2a-c). Liver ultrastructure failed to identify peroxisomes or candidate peroxisomal structures.

Prior to CA treatment initiation, serum ALT and AST were elevated, serum bilirubin was normal, and PT was slightly elevated (Table 2).

\section{Cholic Acid Treatment}

CA $15 \mathrm{mg} / \mathrm{kg} /$ day was started at age 3 years and has been ongoing for 16 years, ranging from 11 to $18.8 \mathrm{mg} / \mathrm{kg} /$ day with no treatment-related adverse effects. Over the course of CA treatment, the patient's liver size normalized and serum liver chemistries stabilized (Table 2). Liver histology at age 4 years, after 1 year of CA treatment, was essentially unchanged, indicating no progression of liver disease (Fig. 2d, e). No hepatocyte steatosis or cholestasis were identified.

\section{Long-Term Outcome}

The patient continues to receive CA therapy. His serum liver chemistries have been stable through age 19 years (Table 2). Within the context of multifaceted medical and supportive treatment, including full-time assistance with daily living activities, he attended regular school with classroom accommodations and graduated from high school. He is a published author of poetry and he has composed music.

\section{Discussion}

Our observational case series suggests that long-term treatment with oral CA may sustain liver function and prevent progression of liver disease in patients with ZSDs who have abnormal liver chemistries at initiation of therapy. In our 3 patients, ongoing CA treatment up to 16 years at the time of this report was associated with stable liver function, as evidenced 


\section{Case Reports in Gastroenterology}

Case Rep Gastroenterol 2018;12:360-372

DOI: $10.1159 / 000490095$

(c) 2018 The Author(s). Published by S. Karger AG, Basel www.karger.com/crg

Heubi et al.: Long-Term Cholic Acid Therapy in Zellweger Spectrum Disorders

from serial serum chemistries, with no treatment-related adverse effects. Consistent with our cases, patients with ZSDs have been shown to survive into adulthood [9]. Early intervention with CA prior to onset of advanced liver disease has been emphasized to minimize progression of liver damage and to maximize the potential for positive treatment outcomes [5]. Liver disease in ZSD may present with early cholestasis and giant cell transformation and progress rapidly to cirrhosis in infants $[5,9]$. The liver disease in our 3 patients was never severe despite presentations in infancy, but subtle signs of mild fibrosis and low-grade progressive liver injury were identified in later biopsies. Angulate lysosomal inclusions in macrophages, as demonstrated in the twins, have been reported previously in ZSD [10]. Importantly, we observed no histologic evidence for progressive disease comparing pre- and posttherapy biopsies over 6 months to 1 year of CA therapy. This finding supports CA treatment for prevention of liver disease progression in patients with ZSD.

The responses of our patients to CA therapy are consistent with a recent report of $15 \mathrm{ZSD}$ patients without advanced liver disease who started CA treatment at ages 2-35 years [5]. Following 9 months of CA therapy, these patients had a significant decline in the bile acid intermediates DHCA and THCA, and liver function tests (AST, ALT, bilirubin) remained stable. Similar to our patient outcomes, although over a much shorter period, there was no progression of liver disease or worsening of liver chemistries. This is in contrast to the apparent disease progression in the remaining 4 ZSD patients with very advanced liver disease at the time of CA treatment initiation who were also described by Berendse et al. [5]. In these patients with cirrhosis and very elevated plasma AST, ALT, and conjugated bilirubin, a small reduction in bile acid intermediates was found, but plasma AST, ALT, and bilirubin increased further during the 9 months of CA treatment. Early intervention with CA before liver disease has progressed to an advanced stage may be vital for optimal responsiveness in ZSD patients.

The mechanisms by which CA therapy may sustain liver function in ZSDs include restoration of the normal physiologic feedback inhibition on bile acid synthesis and replenishment of primary $\mathrm{C}_{24}$-bile acid to stimulate bile flow and increase intraluminal bile acid concentration, with consequent improved absorption of fat and fat-soluble vitamins [6, 7]. In the absence of peroxisomal $\beta$-oxidation of $\mathrm{C}_{27}$-bile acid intermediates to form normal $\mathrm{C}_{24}$-primary bile acids, the main accumulating $\mathrm{C}_{27}$-bile acid intermediates in ZSDs are tauro-THCA, followed by unconjugated THCA, and accumulation of THCA and its more polar metabolites, including $1 \beta$ and $6 \alpha$-hydroxylated derivatives of THCA and side-chain-hydroxylated metabolites $[6,7]$. These atypical bile acids have been associated with hepatic mitochondrial damage [11] and hepatotoxicity $[1,12]$.

ZSD mouse model studies suggest that the effects of CA treatment in ZSD may potentially extend to an important role in the developing central nervous system (CNS). Selective absence of liver peroxisomes, with consequent lack of hepatic peroxisomal metabolism, in the AlfpPex5 knockout mouse model of ZSD has been associated with a persistent deleterious effect on developing neocortex and cerebellum [13]. The major abnormalities in CNS development included disordered lamination of the cortical plate, clustered neurons "stuck" in the intermediate zone, much greater cell death in the cortex and cerebellar impaired foliation, delayed granule cell migration and greater cell death, and stunted Purkinje cell arborization. Alternatively, using a peroxisome-deficient mouse model of ZSD (Pex5 knockout), partial reconstitution of hepatic peroxisome function resulted in a significant improvement in brain neuronal migration [14]. Further, bile acid treatment of newborn mice in the Pex2-/- mouse model of 
ZSD partially restored cerebellar abnormalities and improved dendritic arborization of Purkinje cells [15]. Although the potential role of toxic $\mathrm{C}_{27}$-bile acids in CNS developmental abnormalities is not yet known, increased $\mathrm{C}_{27}$-bile acids in brain tissue have been shown in patients with a peroxisome deficiency disorder compared with control patients [6]. The accumulating $\mathrm{C}_{27}$-bile acid intermediates were unconjugated THCA, DHCA, and OH-THCA, indicating more efficient movement across the blood-brain barrier versus conjugated bile acid intermediates. Altogether, these findings suggest that early intervention with CA in patients with ZSD to sustain liver function may be important for optimal responses beyond hepatic disease. As shown in our patients with ZSDs who continue to receive ongoing CA treatment, long-term CA therapy has sustained stable liver function without treatment-related adverse events, helping to optimize quality of life in these patients.

\section{Statement of Ethics}

The CA treatment that provided the data for this study was under an FDA IND and was approved by the institutional review board of the Cincinnati Children's Hospital Medical Center. All procedures were in accordance with the ethical standards of the responsible committee on human experimentation (institutional and national) and with the Helsinki Declaration of 1975 , as revised in 2000 . The parents of each patient provided informed consent for inclusion in the FDA IND studies and in this report. Documentation is available on request.

\section{Disclosure Statement}

J.E. Heubi: consultant (Alnylam, Nordmark, Retrophin, Inc.); equity interest (Asklepion). K.D.R. Setchell: consultant (Retrophin, Inc.); equity interest (Asklepion). K.E. Bove: no conflicts to report.

\section{Funding Sources}

Writing and editorial support was provided by Lynanne McGuire, PhD, of MedVal Scientific Information Services, LLC, of Princeton, NJ, and was funded by Retrophin, Inc. The manuscript was prepared according to the International Society for Medical Publication Professionals' "Good Publication Practice for Communicating Company-Sponsored Medical Research: GPP3."

\section{Author Contributions}

J.E. Heubi provided ongoing care for the reported patients, conceived the study, provided the patient history data, provided the liver chemistry data and interpretation, helped draft the manuscript, and critically revised the manuscript for content. He serves as guarantor for this article, accepts full responsibility for the work and the conduct of the study, had access to the 
data, and controlled the decision to publish. K.D.R. Setchell performed the bile acid analyses, interpreted data, and critically reviewed the manuscript and offered suggestions for content. K.E. Bove provided analysis/discussion of the liver histopathologic findings in reported patients and critically reviewed the manuscript for content.

\section{References}

1 Wanders RJ, Ferdinandusse S. Peroxisomes, peroxisomal diseases, and the hepatotoxicity induced by peroxisomal metabolites. Curr Drug Metab. 2012 Dec;13(10):1401-11.

2 Klouwer FC, Berendse K, Ferdinandusse S, Wanders RJ, Engelen M, Poll-The BT. Zellweger spectrum disorders: clinical overview and management approach. Orphanet J Rare Dis. 2015 Dec;10(1):151.

3 Braverman NE, Raymond GV, Rizzo WB, Moser AB, Wilkinson ME, Stone EM, et al. Peroxisome biogenesis disorders in the Zellweger spectrum: an overview of current diagnosis, clinical manifestations, and treatment guidelines. Mol Genet Metab. 2016 Mar;117(3):313-21.

4 Baes M, Van Veldhoven PP. Hepatic dysfunction in peroxisomal disorders. Biochim Biophys Acta. 2016 May;1863(5):956-70.

5 Berendse K, Klouwer FC, Koot BG, Kemper EM, Ferdinandusse S, Koelfat KV, et al. Cholic acid therapy in Zellweger spectrum disorders. J Inherit Metab Dis. 2016 Nov;39(6):859-68.

6 Ferdinandusse S, Denis S, Faust PL, Wanders RJ. Bile acids: the role of peroxisomes. J Lipid Res. 2009 Nov;50(11):2139-47.

7 Setchell KD, Bragetti P, Zimmer-Nechemias L, Daugherty C, Pelli MA, Vaccaro R, et al. Oral bile acid treatment and the patient with Zellweger syndrome. Hepatology. 1992 Feb;15(2):198-207.

8 Heubi JE, Bove KE, Setchell KD. Oral cholic acid is efficacious and well tolerated in patients with bile acid synthesis and Zellweger spectrum disorders. J Pediatr Gastroenterol Nutr. 2017 Sep;65(3):321-6.

9 Berendse K, Engelen M, Ferdinandusse S, Majoie CB, Waterham HR, Vaz FM, et al. Zellweger spectrum disorders: clinical manifestations in patients surviving into adulthood. J Inherit Metab Dis. 2016 Jan;39(1): 93-106.

10 Mooi WJ, Dingemans KP, van den Bergh Weerman MA, Jöbsis AC, Heymans HS, Barth PG. Ultrastructure of the liver in the cerebrohepatorenal syndrome of Zellweger. Ultrastruct Pathol. 1983 Sep-0ct;5(2-3):135-44.

11 Mathis RK, Watkins JB, Szczepanik-Van Leeuwen P, Lott IT. Liver in the cerebro-hepato-renal syndrome: defective bile acid synthesis and abnormal mitochondria. Gastroenterology. 1980 Dec;79(6):1311-7.

12 Sundaram SS, Bove KE, Lovell MA, Sokol RJ. Mechanisms of disease: inborn errors of bile acid synthesis. Nat Clin Pract Gastroenterol Hepatol. 2008 Aug;5(8):456-68.

13 Krysko 0, Hulshagen L, Janssen A, Schütz G, Klein R, De Bruycker M, et al. Neocortical and cerebellar developmental abnormalities in conditions of selective elimination of peroxisomes from brain or from liver. J Neurosci Res. 2007 Jan;85(1):58-72.

14 Janssen A, Gressens P, Grabenbauer M, Baumgart E, Schad A, Vanhorebeek I, et al. Neuronal migration depends on intact peroxisomal function in brain and in extraneuronal tissues. J Neurosci. 2003 Oct;23(30): 9732-41.

15 Faust PL, Banka D, Siriratsivawong R, Ng VG, Wikander TM. Peroxisome biogenesis disorders: the role of peroxisomes and metabolic dysfunction in developing brain. J Inherit Metab Dis. 2005;28(3):369-83. 


\begin{tabular}{|c|c|c|}
\hline \multirow{3}{*}{$\begin{array}{r}\text { Case Reports in } \\
\text { Gastroenterology }\end{array}$} & \multirow{2}{*}{\multicolumn{2}{|c|}{ Case Rep Gastroenterol 2018;12:360-372 }} \\
\hline & & \\
\hline & DOI: 10.1159/000490095 & $\begin{array}{l}\text { (c) } 2018 \text { The Author(s). Published by S. Karger AG, Basel } \\
\text { www.karger.com/crg }\end{array}$ \\
\hline
\end{tabular}
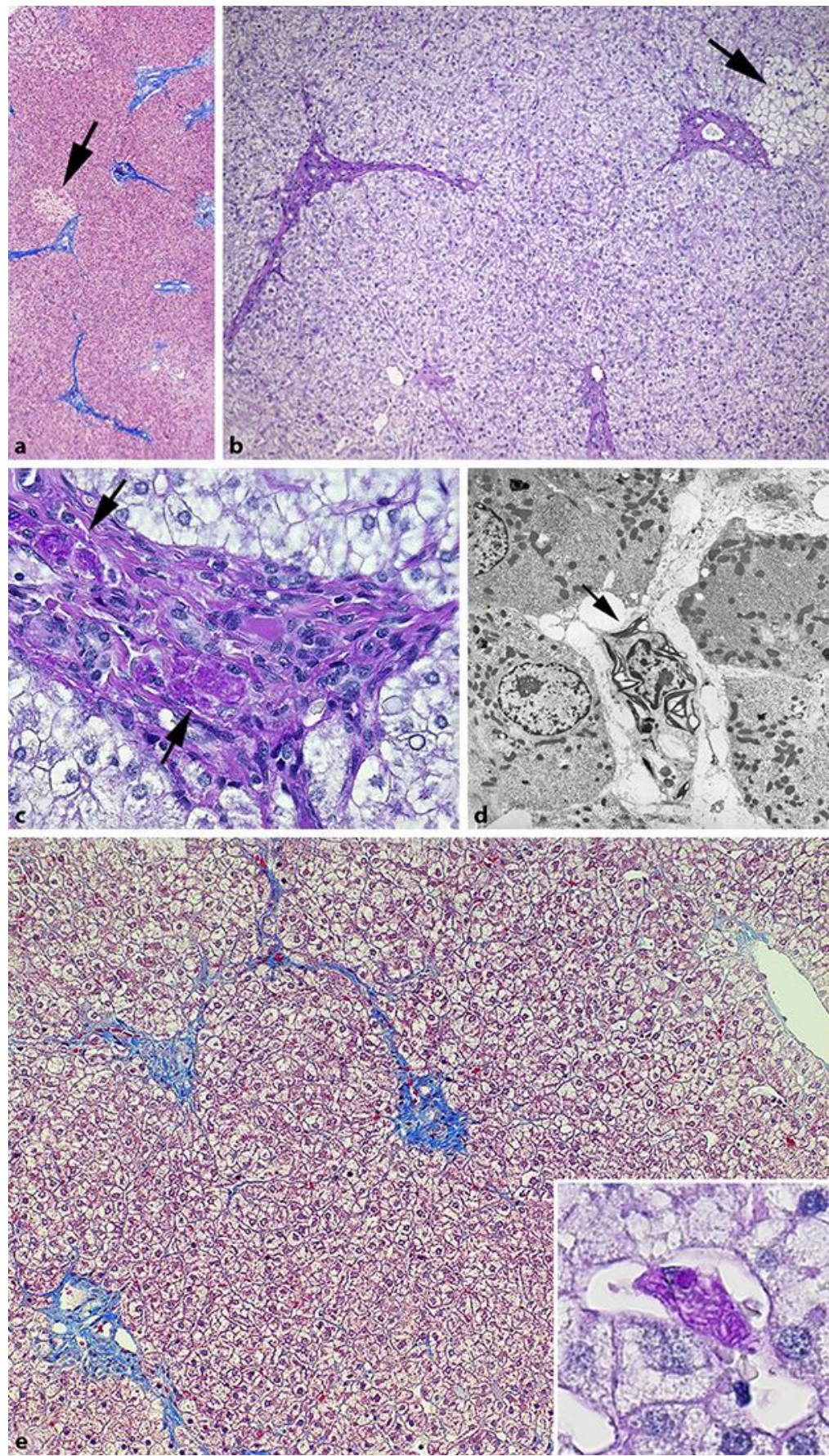


\section{Case Reports in Gastroenterology}

Fig. 1. Liver histology of patient 1 during CA therapy and liver histology of patient 2 before CA therapy. Patient 1: a Portal areas are prominent due to delicate septal fibrosis. Pale pseudonodules are composed of hyperglycogenated hepatocytes (arrow). Trichrome stain, $\times 50$. b Pale hepatocytes with expanded cytoplasm contain excess glycogen, further accentuated in scattered glycogen pseudonodules (arrow). PASdiastase, $\times 100$. $c$ The portal area contains clusters of macrophages with abundant slate-gray granular cytoplasm highlighted by PAS stain (arrows). PAS-diastase stain, $\times 400$. $\mathbf{d}$ Hepatocyte cytoplasm contains excess glycogen granules that displace normal-appearing mitochondria. Peroxisomes are absent. The Kupffer cell (arrow) contains multiple dense polymorphous secondary lysosomes with unusual angulated crystalline profiles. Uranium acetate and lead citrate, $\times 2,500$. Patient 2 : e The portal areas are expanded by delicate fibrous septa. Hepatocyte cytoplasmic clarity is due to mild excess of glycogen. Inset: Expanded cytoplasm in a rare Kupffer cell is storage cell-like with needle-shaped linear inclusions. Main panel: Trichrome stain, $\times 100$. Inset: PAS-diastase stain, $\times 800$. CA, cholic acid. 


\section{Case Reports in Gastroenterology}

Case Rep Gastroenterol 2018;12:360-372

DOI: 10.1159/000490095

(c) 2018 The Author(s). Published by S. Karger AG, Basel www.karger.com/crg

Heubi et al.: Long-Term Cholic Acid Therapy in Zellweger Spectrum Disorders
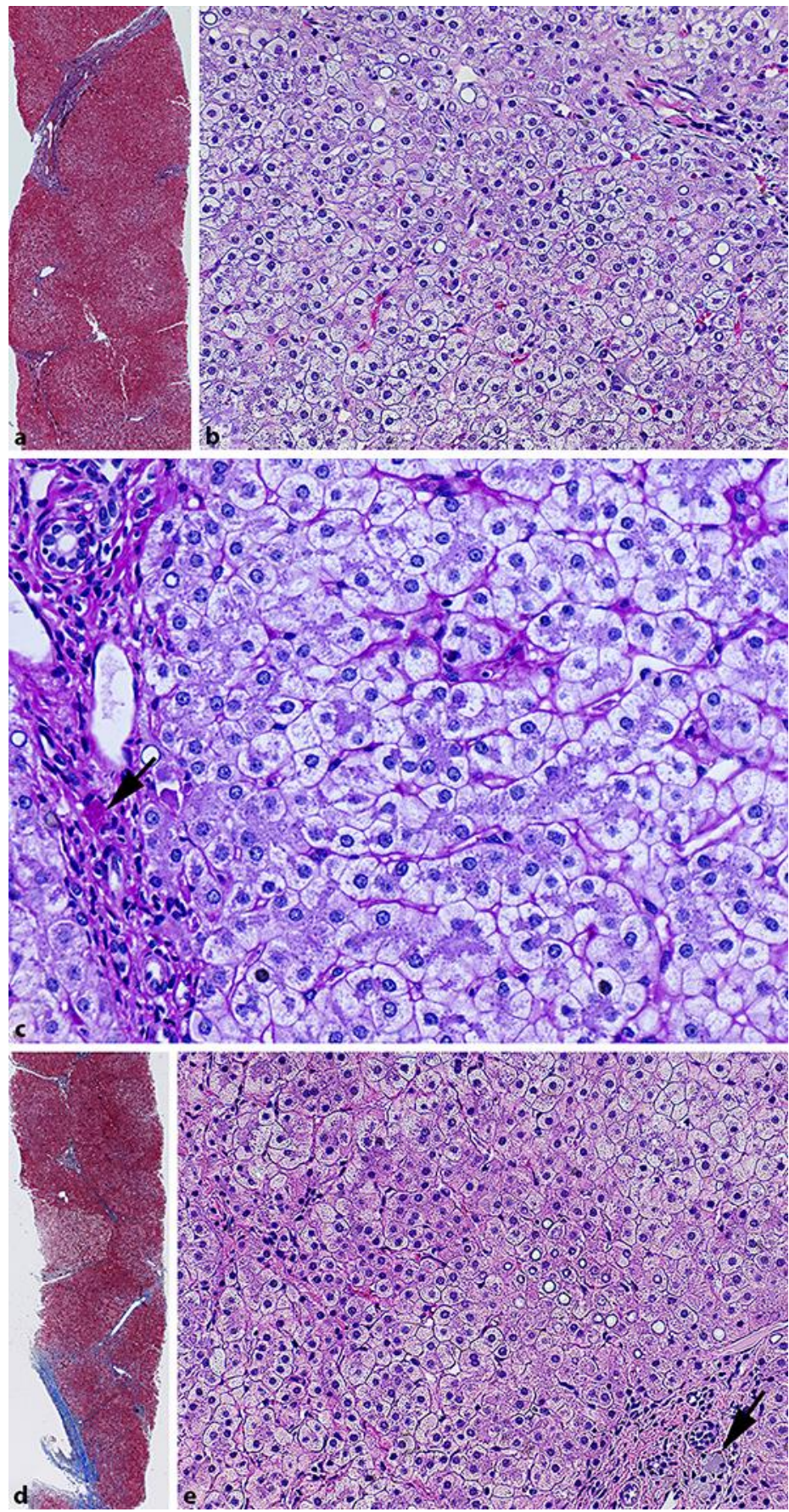
Fig. 2. Liver histology of patient 3 before and during CA therapy. Before CA therapy: a Lobular architecture is accentuated by vague pseudonodularity and focal periportal fibrosis. Trichrome stain, $\times 50$. $\mathbf{b}$ Hepatocyte cytoplasm is clear and mildly expanded. Nuclear glycogen inclusions are prominent in zone 1. H\&E stain, $\times 200$. c All hepatocytes contain mild excess of secondary lysosomes (lipofuscin granules). Scattered portal (arrow) and sinusoidal macrophages contain abundant granular secondary lysosomes. PAS-diastase, $\times 320$. During CA therapy: $\mathbf{d}$ Vague pseudonodularity is due to mild delicate periportal incomplete septal fibrosis. Trichrome stain, $\times 50$. e Hepatocyte appearance is unchanged compared to before CA therapy, including prominence of glycogen nuclear pseudoinclusions in zone 1. Macrophages with slate-gray cytoplasm aggregate in the portal zone (arrow). H\&E stain, $\times 200$. CA, cholic acid.

Table 1. Plasma total lipid very-long-chain and branched-chain fatty acids prior to CA therapy

\begin{tabular}{lllll}
\hline Test & Patient 1 & Patient 2 & Patient 3 & $\begin{array}{c}\text { Reference } \\
\text { range (SD) }\end{array}$ \\
\hline Very-long-chain fatty acids & & & & \\
C22:0, $\mu \mathrm{g} / \mathrm{mL}$ & & & & $16.14(3.77)$ \\
$\mathrm{C} 22: 1 \mathrm{w} 9, \mu \mathrm{g} / \mathrm{mL}$ & 4.245 & 5.009 & $\mathrm{NA}$ & $0.47(0.20)$ \\
$\mathrm{C} 24: 0, \mu \mathrm{g} / \mathrm{mL}$ & 0.577 & $\mathrm{NA}$ & $\mathrm{NA}$ & $13.34(3.78)$ \\
$\mathrm{C} 26: 0, \mu \mathrm{g} / \mathrm{mL}$ & 5.470 & 6.573 & $\mathrm{NA}$ & $0.22(0.08)$ \\
C26:1, $\mu \mathrm{g} / \mathrm{mL}$ & 0.727 & 0.998 & $\mathrm{NA}$ & $0.12(0.05)$ \\
C24/C22 & 0.345 & 1.55 & $\mathrm{NA}$ & $0.84(0.08)$ \\
C26/C22 & 1.288 & 1.314 & 1.737 & $0.01(0.01)$ \\
C26:1/22.0 & 0.171 & 0.200 & 0.170 & $\mathrm{NA}$ \\
Phytanic acid, $\mu \mathrm{g} / \mathrm{mL}$ & $\mathrm{NA}$ & $\mathrm{NA}$ & 0.134 & $0.80(0.40)$ \\
Pristanic acid, $\mu \mathrm{g} / \mathrm{mL}$ & 7.420 & 6.920 & $39.8(\mathrm{nmol} / \mathrm{mL})$ & $0.31(0.41)$ \\
Pipecolic acid (plasma), $\mu \mathrm{mol} / \mathrm{L}$ & 1.951 & 2.265 & 11.9 & $0.5-4.9$ \\
Pipecolic acid (urine), $\mu \mathrm{mol} / \mathrm{g}$ & 108.1 & 66.7 & $\mathrm{NA}$ & $1.6-20.4$ \\
C16:0 DMA/C16:0 fatty acid & $\mathrm{NA}$ & 11.0 & $\mathrm{NA}$ & $0.051-0.090$ \\
C18:0 DMA/C18:0 fatty acid & 0.066 & 0.085 & $\mathrm{NA}$ & $0.137-0.255$ \\
\hline
\end{tabular}

CA, cholic acid; DMA, dimethyl acetals; NA, not available; SD, standard deviation. 
 Gastroenterology}

\begin{tabular}{l|l}
\hline Case Rep Gastroenterol 2018;12:360-372 \\
\hline DOI: 10.1159/000490095 & $\begin{array}{l}\text { ( ) 2018 The Author(s). Published by S. Karger AG, Basel } \\
\text { www.karger.com/crg }\end{array}$ \\
\hline
\end{tabular}

Heubi et al.: Long-Term Cholic Acid Therapy in Zellweger Spectrum Disorders

Table 2. Serum liver chemistries of patients with ZSDs receiving ongoing CA therapy

\begin{tabular}{|c|c|c|c|c|c|c|}
\hline & $\begin{array}{l}\text { ALT, U/L } \\
\text { (RR) }\end{array}$ & $\begin{array}{l}\text { AST, U/L } \\
\text { (RR) }\end{array}$ & $\begin{array}{l}\text { ALP, U/L } \\
\text { (RR) }\end{array}$ & $\begin{array}{l}\text { Total bilirubin, } \\
\text { mg/dL (RR) }\end{array}$ & $\begin{array}{l}\text { PT, s } \\
\text { (RR) }\end{array}$ & INR \\
\hline \multicolumn{7}{|l|}{ Patient 1} \\
\hline Pre-CA (age 13 months) & $39(5-45)$ & $129(20-60)$ & $261(145-320)$ & NA & $12.1(10.3-13.5)$ & 1.0 \\
\hline 6 months CA therapy & $9(5-45)$ & $86(20-60)$ & $292(145-320)$ & NA & $13.3(10.6-13.8)$ & NA \\
\hline 10 months CA therapy & $72(4-40)$ & $74(4-40)$ & $266(50-300)$ & NA & NA & 1.2 \\
\hline 1 year 4 months CA therapy & $41(8-45)$ & $61(8-45)$ & $436(35-125)$ & $0.3(<1.3)$ & NA & NA \\
\hline 3 years 5 months CA therapy & $47(11-66)$ & $67(10-46)$ & $347(40-468)$ & $0.8(0.0-1.3)$ & $12.0(10.2-13.0)$ & 1.2 \\
\hline 9 years 5 months CA therapy & $43(21-72)$ & $60(17-59)$ & $303(30-315)$ & $0.4(0.2-1.3)$ & $13.4(10.5-15.0)$ & 1.2 \\
\hline 13 years 6 months CA therapy & $70(8-31)$ & $65(17-38)$ & $587(0-900)$ & $0.67(<1.0)$ & NA & NA \\
\hline 15 years 7 months CA therapy & $25(7-55)$ & $35(10-50)$ & $181(70-260)$ & $0.3(0.0-1.2)$ & $14.1(12.0-16.1)$ & 1.0 \\
\hline \multicolumn{7}{|l|}{ Patient 2} \\
\hline Pre-CA (age 19 months) & $72(5-45)$ & $78(20-60)$ & $458(145-320)$ & NA & $12.4(10.6-13.8)$ & 1.0 \\
\hline 4 months CA therapy & $55(4-40)$ & $67(4-40)$ & $479(50-300)$ & NA & 13.6 (NA) & 1.2 \\
\hline 10 months CA therapy & $58(8-45)$ & $61(8-45)$ & $564(35-125)$ & $0.3(<1.3)$ & 14.6 (NA) & NA \\
\hline 2 years 11 months CA therapy & $86(11-66)$ & $110(10-46)$ & $369(40-468)$ & $0.9(0.0-1.3)$ & $11.1(10.2-13.0)$ & 1.1 \\
\hline 8 years 11 months CA therapy & $45(21-72)$ & $57(17-59)$ & $288(30-315)$ & $0.9(0.2-1.3)$ & $12.5(10.5-15.0)$ & 1.1 \\
\hline 13 years CA therapy & $149(9-41)$ & $75(14-32)$ & $504(<900)$ & $0.5(<1.0)$ & NA & NA \\
\hline 15 years CA therapy & $27(7-45)$ & $32(10-50)$ & $124(70-260)$ & $0.6(0.0-1.2)$ & $13.2(12.0-16.1)$ & 1.0 \\
\hline \multicolumn{7}{|l|}{ Patient 3} \\
\hline Pre-CA (age 3 years) & $83(5-45)$ & $130(10-60)$ & NA & NA & $14.2(10.3-13.5)$ & 1.4 \\
\hline 3 months CA therapy & $81(5-45)$ & $129(10-60)$ & $190(30-200)$ & $0.3(0.2-1.2)$ & $14.0(11.3-13.3)$ & 1.3 \\
\hline 1 year CA therapy & $40(7-50)$ & $68(15-35)$ & $166(40-112)$ & $0.0(0.2-1.0)$ & NA & NA \\
\hline 2 years 2 months CA therapy & $72(10-45)$ & $125(10-60)$ & $257(30-200)$ & $0.1(0.2-1.2)$ & $17.0(11.1-13.0)$ & 1.5 \\
\hline 5 years CA therapy & $46(7-50)$ & $72(15-35)$ & $158(40-112)$ & $0.6(0.2-1.0)$ & $15.2(\mathrm{NA})$ & 1.5 \\
\hline 8 years 8 months CA therapy & $50(8-40)$ & $65(15-41)$ & $148(24-280)$ & $0.7(0.4-1.5)$ & $12.7(10.1-13.1)$ & 1.1 \\
\hline 12 years 3 months CA therapy & $86(8-36)$ & $90(13-38)$ & $170(67-372)$ & $0.2(0.2-1.4)$ & NA & NA \\
\hline 16 years CA therapy & $88(8-36)$ & $66(13-38)$ & $86(52-171)$ & $0.5(0.2-1.4)$ & $12.3(9.6-11.7)$ & 1.1 \\
\hline
\end{tabular}

Bold values are above the reference range. Gamma-glutamyl transpeptidase (data not shown) was normal in all 3 patients. ALP, alkaline phosphatase; ALT, alanine aminotransferase; AST, aspartate aminotransferase; CA, cholic acid; INR, international normalized ratio; NA, not available; PT, prothrombin time; RR, reference range; ZSDs, Zellweger spectrum disorders. 